\title{
An Improved Monte Carlo Method Based on Neural Network and Fuzziness Analysis: A Case Study of the Nanpo Dump of the Chengmenshan Copper Mine
}

\author{
Feng Gao $\mathbb{D}$, Xiaodong $W u(\mathbb{D}$, and LeWen $W u(\mathbb{D}$ \\ School of Resources and Safety Engineering, Central South University, Changsha 410083, China \\ Correspondence should be addressed to Feng Gao; csugaofeng@126.com
}

Received 22 October 2020; Revised 30 November 2020; Accepted 28 December 2020; Published 15 January 2021

Academic Editor: Chih-Cheng Hung

Copyright (c) 2021 Feng Gao et al. This is an open access article distributed under the Creative Commons Attribution License, which permits unrestricted use, distribution, and reproduction in any medium, provided the original work is properly cited.

\begin{abstract}
The landslide of dump is a man-made geological disaster which will bring great harm to the surrounding people and environment, and probabilistic reliability analysis is commonly used to analyze the probability of slope landslide or whether protective measures should be taken. Monte Carlo simulation is the most commonly used method, but there are some problems, such as low efficiency, statistical ambiguity of small samples, and the fuzzy transition interval of the stability criterion. This paper proposes an improved Monte Carlo method that uses an improved bootstrap method to process small samples of geotechnical data, employs ELM (extreme learning machine) based on PSO (particle swarm optimization) to fit the limit equilibrium method function, and constructs the safety factor membership function of the dump site considering the fuzzy transition interval. This method was applied to an example slope of the dump site in Chengmenshan, Jiangxi. Comparing the analysis result with the result of the traditional MCS (Monte Carlo Search) method, it was found that after adding the safety factor membership function, the result was closer to the actual situation of the dump site, and the probability of failure and reliability index values were closer to those of the dangerous state; after the original function was replaced by the PSO-ELM model, the efficiency of the MCS method was greatly improved while the results maintained high consistency with the original results; the MCS method combined with the bootstrap method not only simulated the fuzzy uncertainty of the original sample statistics and distribution type but also expressed the reliability index and probability of failure as a two-sided confidence interval with a certain confidence level. The above conclusion proves the effectiveness and superiority of this method compared with the original MCS method.
\end{abstract}

\section{Introduction}

As a man-made geological disaster with the rise of mining industry, dump landslide not only threatens the life and property safety of mine personnel but also has a huge impact on the surrounding environment. Dump sites in mining areas have been studied by domestic and foreign scholars for stability analysis. At present, the most commonly used methods [1] in engineering are the limit equilibrium method and numerical analysis based on the finite element method, obtaining a certain safety factor value of the analyzed slope and clarifying the sliding surface or part that is most likely to be damaged. However, it often ignores widespread uncertainty of slopes' stability analysis (such as the uncertainty of the calculation parameters of the rock and soil, the geometric model, and the functional relationship between the slopeinfluencing factors and the safety factor), so the effect is not satisfactory. Reliability analysis introduces probability theory into the slope stability evaluation system and obtains the slope failure probability and reliability index based on consideration of the above uncertain factors, so as to achieve a more reasonable and scientific evaluation of the stability of the slope. In recent years, it has been widely valued and studied by scholars.

The reliability analysis methods of soil slopes can be roughly divided into the first-order second moment method [2-8], Monte Carlo method [9-14], and response surface method [11, 15-23]. Among them, the Monte Carlo method is favored in soil slope reliability analysis due to its accuracy and ease of operation (no matter how complicated the limit 
state equations and calculations are, according to statistical principles, only enough simulation sampling times and random number sequences are needed to obtain an accurate failure probability value), but some problems also exist.

Firstly, the original limit equilibrium iterative calculation method that links the soil parameters and the slope safety factor requires a certain amount of time, and the Monte Carlo method has to repeat the process hundreds of thousands or even millions of times, so a huge amount of time is needed. Many scholars use models from other fields to simulate and approximate the functional relationship between slope safety factors and soil parameters to solve the problem of low efficiency. He [24] used sample data obtained by deterministic calculations to train a support vector machine (SVM) model to approximate the functional function in the reliability analysis and then combined it with the Monte Carlo method to calculate the probability of slope instability. After the application, it was proved that the accuracy of this method was better than the (first-order reliability method) FORM method, and the efficiency was higher than the ordinary MCS method. Tan et al. [25] proposed a method to replace the original functional function in reliability analysis with an SVM and (radial basis function) RBF model fitted based on two new sample selection methods and combined different examples to illustrate the accuracy and efficiency of the two. Su [26] constructed a Monte Carlo method based on Gaussian regression response surface and verified the effectiveness and efficiency of the method through three slope calculation examples. In addition, artificial bee colony evolution algorithm [27], artificial neural network [28], Kriging [29-31], and vector projection [32] have been used to construct the functional relationship between input parameters and output safety factors, alleviating the problem of low efficiency to a certain extent.

Secondly, the traditional MCS method also has the problem of fuzziness. Fuzziness is mainly reflected in two aspects: the traditional reliability analysis using $Z<0$ as the criterion to judge slope failure is too arbitrary, ignoring the fuzzy interval of the intermediate transition between stability and instability, and the variability of the sample mean and standard deviation caused by insufficient sample test data will further cause fuzzy uncertainty of the soil parameter distribution types and statistics and ultimately affect the reliability calculation results. In response, some scholars try to solve these problems from the perspective of combining fuzzy mathematics theory and mathematical statistics methods. Habibagahi and Meidani [33], Xu et al. [34], Jia and He [35], Lou [36], Xu [37], Anvar et al. [38], and others successively established the membership function between safety factor and slope stability based on fuzzy mathematics theory. The membership function form has undergone an evolution from linear to nonlinear, triangular to trapezoidal and then to ridge distribution, and it has become closer to the reality of slope stability. However, the ways to determine the undetermined coefficients of the membership function are relatively scarce and subjective. It is necessary to collect as many corresponding slope examples as possible to help judge the rationality of the membership function. Most and Knabe [39], Luo et al. [40], and Tang [41] used the well-known bootstrap theory in statistics to expand the sample in order to reduce the turbulence of the reliability calculation caused by the variability of the parameter sample mean, standard deviation, and distribution, and the reliability index can be more reasonably characterized as a confidence interval with a certain confidence level. This will not only fully simulate the variability of sample statistics, distribution types, and reliability calculation results but also make the slope reliability calculation results more reasonable and true. However, the current combination of bootstrap and Monte Carlo methods is rarely applied, because each bootstrap subsample generated by sampling requires a Monte Carlo calculation, which brings a huge computational burden, so it is necessary to combine some measures to improve the efficiency of the Monte Carlo method.

The Chengmenshan Copper Mine in Jiujiang, Jiangxi Province, due to site selection constraints, had to construct a dump in the lake area near the mining area where the base bearing capacity is weak. In addition, the height of the heap load is relatively high, so it is very easy for progressive landslide instability to be produced over time. Wang [1] conducted a comprehensive reliability analysis on the traditional MCS used in the Chengmenshan dump site (natural unsupported state); the average value of the calculation results under different limit equilibrium functions is $P_{f}=6.65 \%, \beta=1.71$, and the results of different methods are highly variable. According to the 1997 US Army Corps of Engineers Index [42], the situation is between unsatisfactory and poor, which is slightly different from the actual situation of the Nanpo dump site (support measures are needed to prevent landslide). The reason might be that the statistical uncertainty caused by insufficient rock and soil samples and the fuzziness of the traditional MCS method were ignored.

According to the question above, an improved Monte Carlo method was proposed that uses improved bootstrap methods to process small samples of geotechnical data, applies particle swarm optimization (PSO)-optimized extreme learning machine (ELM) to fit limit equilibrium method function, and constructs the safety factor membership function of the dump site considering the fuzzy transition interval. It was applied to the reliability analysis of the second-stage dump site of Chengmenshan Copper Mine, and the results were compared with those of the traditional MCS method for the purpose of verifying effectiveness and rationality of the improved Monte Carlo method.

\section{Traditional Monte Carlo Analysis of Chengmenshan Dump}

2.1. Overview of the Dump. Chengmenshan Copper Mine is located in Chengmen Town, Jiujiang, Jiangxi. The secondstage dump site is located at the Nanpo ravine and Dachengmen valley on the southeast side of the slope. It is divided into two parts: Nanpo (south slope) and Chengmengou dump sites. The climate in the mining area has four distinct seasons, humid, hot spring/summer, cold, and dry autumn/winter, the annual average temperature is $17^{\circ} \mathrm{C}$, and the annual average precipitation is $1420 \mathrm{~mm}$. The basement of the dump site on the south slope is generally a slippery stratum. When the overlying waste material accumulates to a certain extent, under the pressure of its own weight and 
external factors, it is easy for a slip surface to be produced along the slippery bottom layer to the slope surface area and cause a landslide accident. So far, many bottom heaves of dump slope have been found.

The second-stage dump site of the mine has six characteristic sections within the delineated area. Section E-E in the eastern part of the Nanpo dump site was selected for analysis (natural unsupported state). A cross-sectional view is shown in Figure 1, and the statistical characteristics of the 20 experimental datasets and 14 expanded datasets are shown in Table 1. In the process of parameter sampling, the cohesion and internal friction angle of rock and soil mass meet the linear negative correlation, and the correlation coefficient is taken as -0.5 .

\subsection{Results of Traditional Monte Carlo Slope Reliability} Analysis(LimitEquilibrium) Method. For geotechnical slope engineering, the state function of the slope's stability can be expressed as

$$
Z=g\left(X_{1}, X_{2}, X_{3}, \ldots, X_{m}\right),
$$

where the value of the state function $Z$ is the safety factor and $X_{1}, X_{2}, X_{3}, \ldots, X_{m}$ are $m$-many random variables with a certain distribution, which are generally the key factors affecting the stability of a slope such as cohesion and severity of rock and soil. The number of times when the safety factor value $Z \leq 1$ is counted as $M$ and the total number of simulations is $N$, and then the probability of failure can be obtained according to the law of large numbers:

$$
P_{f}=\frac{M}{N} \text {. }
$$

The reliability index can be expressed as

$$
\beta=\Phi^{-1}\left(1-P_{f}\right)
$$

Using different limit equilibrium methods to calculate the safety factor, it was found that the values obtained by the Janbu simplified method were the lowest, so this method was used for subsequent calculation. Slide is a two-dimensional slope stability analysis software based on limit equilibrium method produced by Canadian Rocscience company and is highly praised in engineering applications due to its advantages of practicality, high efficiency, and accuracy. The reliability analysis results obtained by "slide" software using the MCS method are shown in Figure 2, the failure probability of the Nanpo slope dump of the copper mine is $P_{f}=$ $15.25 \%$ and the reliability index is $\beta=1.026$ (also expressed by RI), and the average value of safe factors is 1.045 . The results showed that the slope is basically in a stable state at the end of dumping, but there is a lack of sufficient safety factor reserve, so landslide accidents are very easy to occur under static conditions. Compared with the actual situation, the calculation results tend to be conservative.

\subsection{Problems}

Problem 1. It was found that the corresponding probability of failure varies greatly when using different limit equilibrium methods for MCS calculation. By the Janbu simplified method, it was $15.25 \%$, and by the Bishop simplification method and Spencer's method, it was about $1.1 \%$, and the relative error reached $92.4 \%$. The reason should be that the basis for judging the state of the slope based on whether the safety factor is greater than 1 does not conform to the actual situation. The safety factor calculated by the simplified method for the Nanpo slope dump of the Chengmenshan Copper Mine is basically around the critical value 1; although calculated by other methods (such as the Bishop simplified method), it is only 0.05 higher than the Janbu simplified method. The distribution is mostly on the right side of the critical value 1 , so there is a problem of large differences in failure probability (as shown in Figure 3). And the accuracy of the calculation results under this criterion will also be affected. So, it is necessary to introduce a stable membership function $\mu(z)$ containing the safety factor of the intermediate transition state to improve the judgment method of the slope state in traditional reliability analysis.

Problem 2. The limit equilibrium program realized in MATLAB not only needs to input the sliding surface coordinates, number of blocks, trial radius, soil parameters, and boundary coordinates and other parameters in advance [43] but also needs to simplify the geometric model boundary to a neatly planned boundary and combine some optimized algorithms (such as genetic algorithm [44]) to help search for minimum safety factors. In this paper, the results of running the MCS method in MATLAB are $P_{f}=$ $15.8 \%$ and $\beta=0.998$, and the time consuming is $63005.44 \mathrm{~s}$.

The calculation efficiency of the original MCS method has been criticized, and the bootstrap sampling method needs to repeat the whole process of Monte Carlo simulation tens of thousands or even hundreds of thousands of times, which will take a huge amount of time, so other fast and accurate methods are needed to replace the iterative calculation of the limit equilibrium method in MATLAB.

Problem 3. Due to various reasons in actual slope engineering, the experimental data of rock and soil parameters are often limited, so is this dump (there are only 20 sets of data). The statistical uncertainty caused by small sample may lead to deviations in the subsequent Monte Carlo calculation results.

The following part of this article will focus on methods and applications to solve the above problems.

\section{Methodology}

3.1. Improved Bootstrap Method. Bootstrapping is an effective method to solve the statistical uncertainty of small sample data. The idea of the bootstrap method is to randomly sample the initial samples with replacement to obtain a large number of bootstrap subsamples (the sample size is the same as the original sample) that contain the original sample information, then calculate the estimated value of statistics and Akaike information criterion (AIC) value for each subsample, get their optimal probability density distribution according to the AIC [45], and finally perform Monte Carlo calculation to 


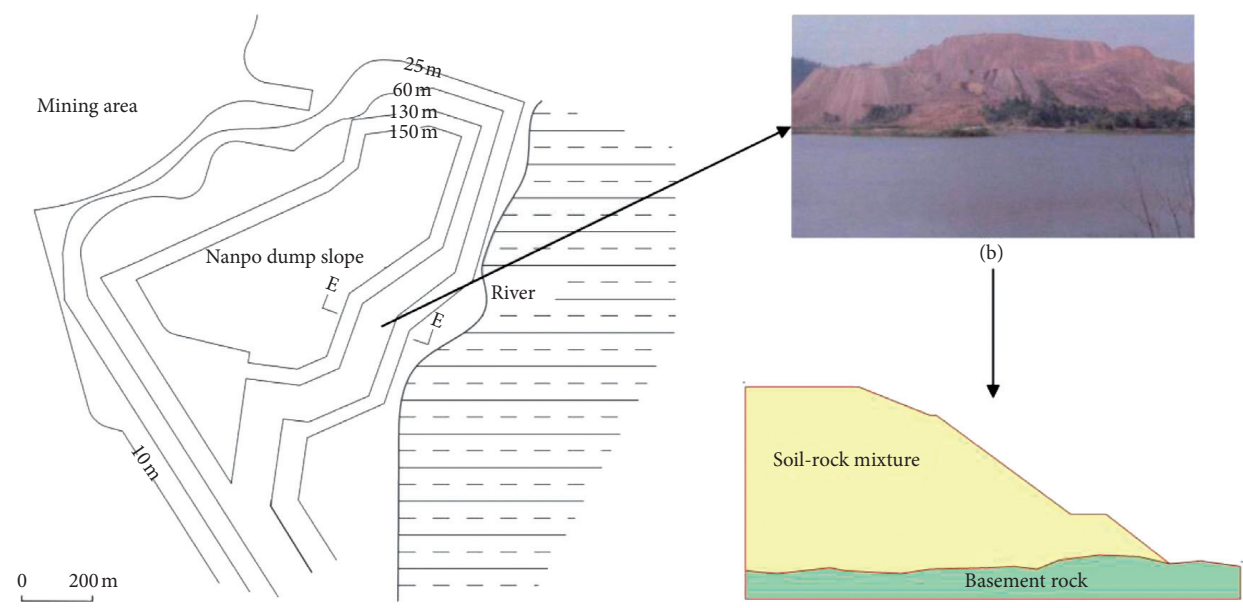

(a)

(c)

FIgure 1: (a) Contour map of Nanpo dump site; (b) real view of E-E section of dump; (c) calculation model of E-E section of dump.

TABLE 1: Statistics of rock and soil parameters.

\begin{tabular}{|c|c|c|c|c|c|c|c|}
\hline \multirow[b]{2}{*}{ Number } & & \multicolumn{3}{|c|}{ Soil-rock mixture } & \multicolumn{3}{|c|}{ Basement rock } \\
\hline & & $\begin{array}{c}\text { Cohesion c } \\
(\mathrm{kPa})\end{array}$ & $\begin{array}{l}\text { Internal friction } \\
\text { angle } \varphi\left({ }^{\circ}\right)\end{array}$ & $\begin{array}{c}\text { Bulk density } \\
\gamma\left(\mathrm{kN} \cdot \mathrm{m}^{-3}\right)\end{array}$ & $\begin{array}{c}\text { Cohesion } \mathrm{c} \\
(\mathrm{kPa})\end{array}$ & $\begin{array}{l}\text { Internal friction } \\
\text { angle } \varphi\left(^{\circ}\right)\end{array}$ & $\begin{array}{c}\text { Bulk density } \\
\gamma\left(\mathrm{kN} \cdot \mathrm{m}^{-3}\right)\end{array}$ \\
\hline \multirow{20}{*}{ Original 20 samples } & 1 & 38.3 & 23.5 & 17.3 & 913 & 17.1 & 26.5 \\
\hline & 2 & 41.4 & 20.5 & 16.9 & 918.82 & 17.66 & 22.07 \\
\hline & 3 & 39.9 & 26.2 & 17.1 & 914.5 & 17.27 & 22.24 \\
\hline & 4 & 34.3 & 20.4 & 17.6 & 909.8 & 16.87 & 22.82 \\
\hline & 5 & 38.1 & 25 & 18.3 & 904.1 & 14.94 & 19.16 \\
\hline & 6 & 43.1 & 24 & 17.1 & 912.8 & 18.422 & 27.76 \\
\hline & 7 & 41.5 & 24.1 & 17.0 & 915.5 & 18.21 & 25.31 \\
\hline & 8 & 36.4 & 22 & 17.6 & 910.7 & 14.75 & 22.93 \\
\hline & 9 & 45 & 25 & 19.7 & 909.2 & 16.78 & 27.61 \\
\hline & 10 & 41.4 & 25.96 & 17.2 & 902 & 18.035 & 20.834 \\
\hline & 11 & 43.4 & 26 & 17.83 & 914.7 & 14.807 & 27.83 \\
\hline & 12 & 38.2 & 20.1 & 16.16 & 909.7 & 16.976 & 27.79 \\
\hline & 13 & 40.5 & 19.8 & 17.92 & 907.9 & 19.55 & 18.98 \\
\hline & 14 & 44.3 & 23.7 & 16.07 & 926 & 19.8 & 18.55 \\
\hline & 15 & 32.4 & 23.3 & 17.9 & 882 & 17.1 & 24.37 \\
\hline & 16 & 37.8 & 24 & 17.64 & 919.7 & 16.78 & 24.06 \\
\hline & 17 & 35.6 & 23.5 & 14.7 & 900.6 & 13.07 & 25.3 \\
\hline & 18 & 35.6 & 22 & 17.3 & 911.9 & 17.58 & 25.29 \\
\hline & 19 & 35.8 & 20.5 & 17.6 & 917.2 & 13.59 & 22.69 \\
\hline & 20 & 36.1 & 23.96 & 22.22 & 917.8 & 17.1 & 24.53 \\
\hline \multirow{14}{*}{$\begin{array}{l}14 \text { sets of samples } \\
\text { after expansion }\end{array}$} & 21 & 36 & 24.3 & 19.92 & 886 & 15.2 & 24.7 \\
\hline & 22 & 46.9 & 19.8 & 16.4 & 892.2 & 13.3 & 27.9 \\
\hline & 23 & 41.9 & 19.69 & 19.42 & 931.1 & 19.74 & 24.23 \\
\hline & 24 & 36.4 & 27 & 18.8 & 908.5 & 18.87 & 18.08 \\
\hline & 25 & 38.8 & 24.7 & 13.9 & 919.2 & 12.97 & 25.81 \\
\hline & 26 & 32.2 & 22.7 & 22.1 & 923.4 & 12.87 & 19.6 \\
\hline & 27 & 42.1 & 19.94 & 17.4 & 882.7 & 17.92 & 21.23 \\
\hline & 28 & 33.8 & 23.28 & 14.62 & 918.3 & 15.81 & 17.81 \\
\hline & 29 & 43.4 & 25.61 & 15.4 & 898.5 & 20.12 & 18.3 \\
\hline & 30 & 37.3 & 19.84 & 23.1 & 902.9 & 17.38 & 23.5 \\
\hline & 31 & 39.9 & 23.28 & 17.73 & 916.6 & 19.3 & 28.5 \\
\hline & 32 & 39.5 & 26.31 & 22.54 & 913.8 & 17.2 & 18.7 \\
\hline & 33 & 40.3 & 22.9 & 18.18 & 920.8 & 16.4 & 28.3 \\
\hline & 34 & 42.7 & 25.4 & 16.81 & 881.2 & 20.03 & 26.9 \\
\hline
\end{tabular}


TABLE 1: Continued.

\begin{tabular}{lccccccc}
\hline Number & \multicolumn{3}{c}{ Soil-rock mixture } & \multicolumn{3}{c}{ Basement rock } \\
& $\begin{array}{c}\text { Cohesion c } \\
(\mathrm{kPa})\end{array}$ & $\begin{array}{c}\text { Internal friction } \\
\text { angle } \varphi\left({ }^{\circ}\right)\end{array}$ & $\begin{array}{c}\text { Bulk density } \\
\gamma\left(\mathrm{kN} \cdot \mathrm{m}^{-3}\right)\end{array}$ & $\begin{array}{c}\text { Cohesion c } \\
(\mathrm{kPa})\end{array}$ & $\begin{array}{c}\text { Internal friction } \\
\text { angle } \varphi\left({ }^{\circ}\right)\end{array}$ & $\begin{array}{c}\text { Bulk density } \\
\gamma\left(\mathrm{kN} \cdot \mathrm{m}^{-3}\right)\end{array}$ \\
\hline $\begin{array}{l}34 \text { sets of samples } \\
\text { after expansion }\end{array}$ & $\begin{array}{c}\text { Mean } \\
\text { Standard } \\
\text { deviation }\end{array}$ & 39.2 & 23.39 & 17.86 & 909.2 & 16.86 & 23.53 \\
\hline \multirow{2}{*}{ Original 20 samples } & $\begin{array}{c}\text { Mean } \\
\text { Standard } \\
\text { deviation }\end{array}$ & 3.69 & 2.20 & 23.18 & 17.64 & 908.7 & 16.78 \\
\hline
\end{tabular}

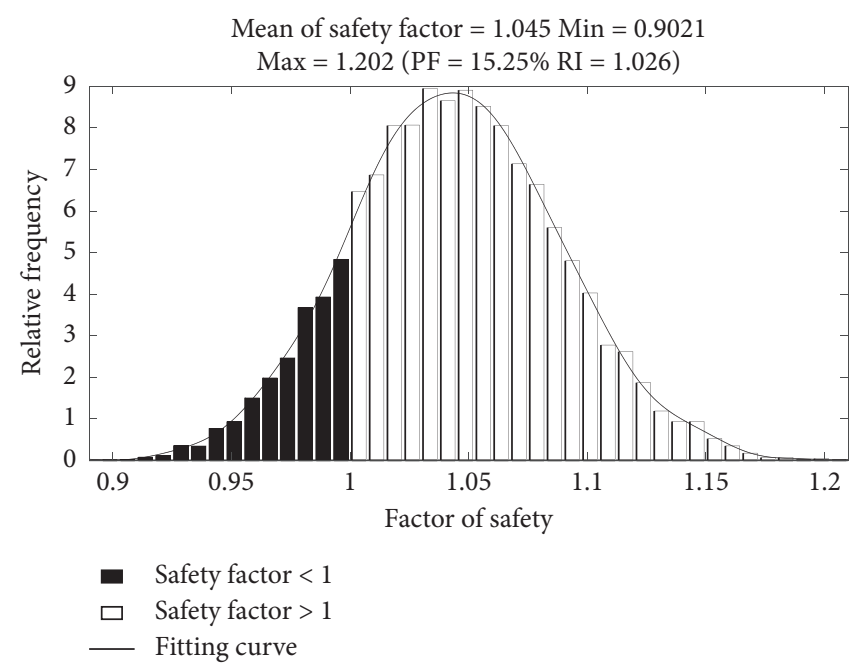

FIgUre 2: Monte Carlo sampling calculation results.

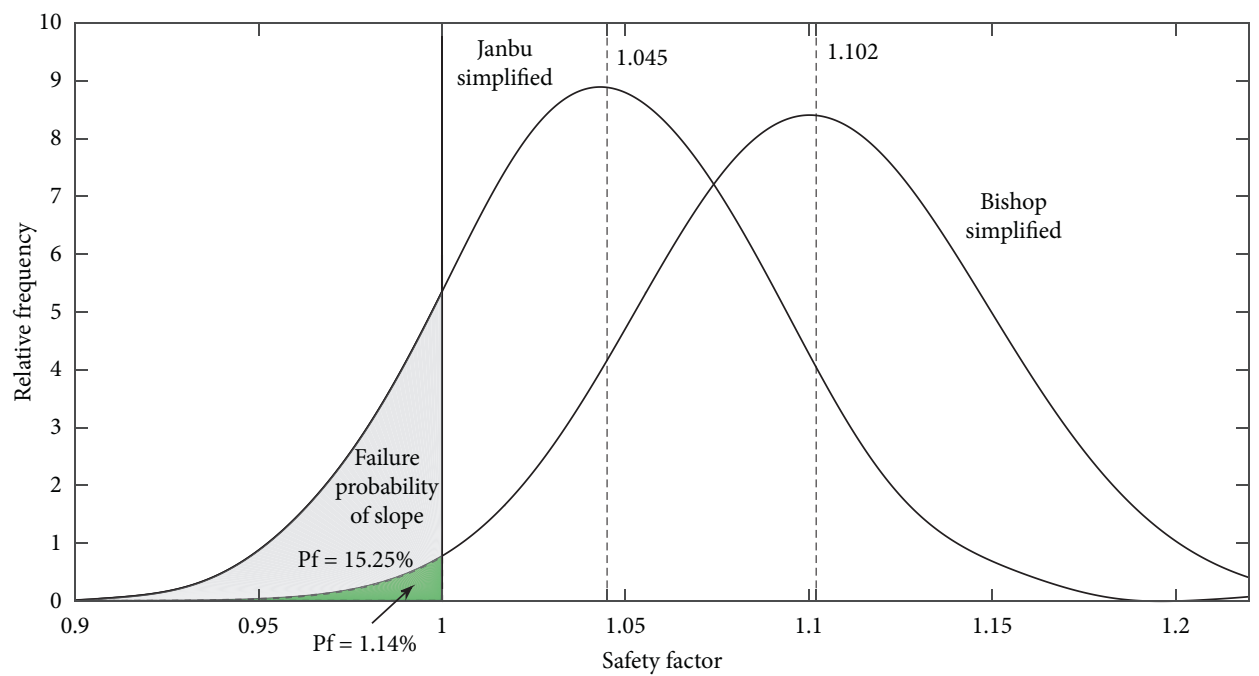

FIGURE 3: Differences in failure probability between limit equilibrium methods.

obtain their reliability index, probability of failure, and corresponding confidence interval.

Assume the sample of soil parameters $X=\left\{\left(c_{i}, \varphi_{i}, \gamma_{i}\right), i=1,2, \ldots, N\right\}$, then randomly sample with replacement $N$ times as shown in Figure 4 to obtain a bootstrap subsample $B_{j}=\left\{B_{1, j}, B_{2, j}, \ldots, B_{N, j}\right\}$, and repeat this step $M$ times to obtain $M$ subsamples.
The theoretical basis and good convergence of the bootstrap method have long been proved by scholars, but it also has the problem that the sampling range is small and the probability distribution is concentrated on a small number of points for small samples (sample size of 10-30), which causes the calculation results to deviate from the true distribution. Some scholars [46-48] proposed an improved 


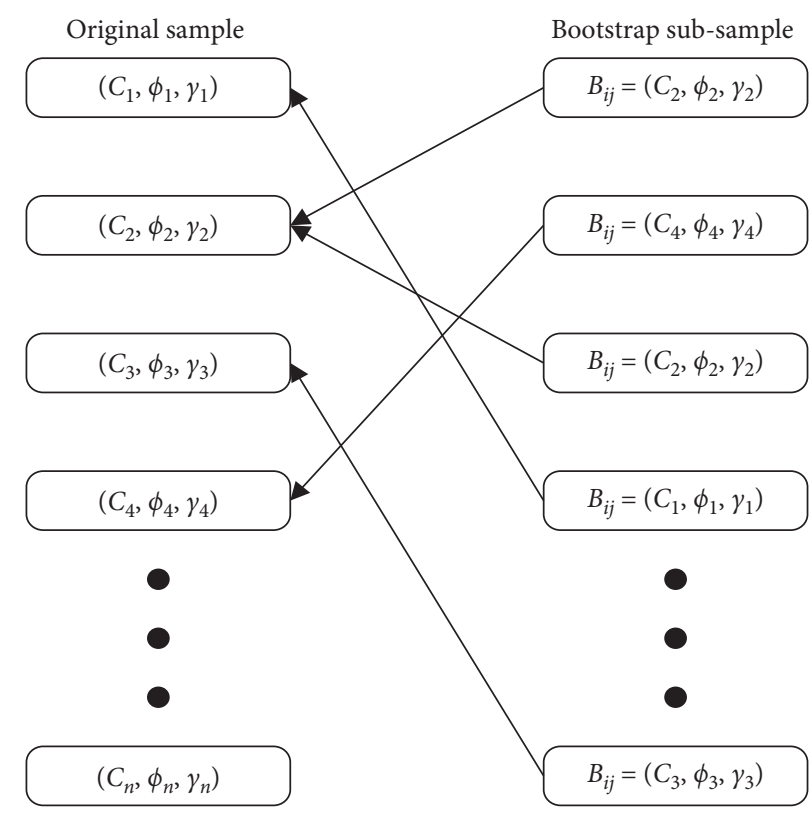

FIGURE 4: Bootstrap self-sampling method.

bootstrap method for this problem: first arrange the original sample in ascending order to get the order statistic $X=\left(x_{1}, x_{2}, x_{3}, \ldots, x_{n}\right)$, then, for each observation $x_{i}$, a larger and a smaller statistic are randomly selected in its neighborhood $U_{i}$ according to the rule of uniform distribution to expand the sampling range and obtain information outside the observation point:

$$
U=\left\{\begin{array}{l}
U_{1}=\left[x_{1}-\frac{x_{2}-x_{1}}{m}, x_{1}+\frac{x_{2}-x_{1}}{m}\right], \\
U_{i}=\left[x_{i}-\frac{x_{i}-x_{i-1}}{m}, x_{i}+\frac{x_{i+1}-x_{i}}{m}\right], \\
U_{n}=\left[x_{n}-\frac{x_{n}-x_{n-1}}{m}, x_{n}+\frac{x_{n}-x_{n-1}}{m}\right], \\
(i=1,2,3, \ldots, n-1, n,)(m \geq 2) .
\end{array}\right.
$$

The bootstrap method can continue to be used for parameter estimation based on the improved samples $X^{\prime}=$ $\left(x_{1}^{\prime}, x_{2}^{\prime}, \ldots, x_{n}^{\prime}\right)$ obtained by formula (4). Since the original sample size of 20 is less than 30 , thus is a small sample, the size can be expanded by formula (4) before bootstrap sampling, but not every observation value needs to be expanded in this way, especially when it is very close to (or even the same as) an adjacent value. Use MATLAB for random permutation and combination after the six groups of data were, respectively, expanded, and the expanded sample statistics are shown in Table 1.

One of four types of functions commonly used in the distribution of rock and soil parameters, normal, lognormal, extreme value I-type, and Wilber distribution, is selected by calculate the AIC value of the original sample (the probability distribution function with the smallest AIC value can be considered as the one that best fits the probability distribution of the test data). It is found that the AIC value corresponding to the normal distribution is the smallest and the optimal probability distributions of the six types of data of the initial sample are all normal distributions, which conforms to the description in the literature [1].

The subsample mean, standard deviation, and optimal probability density function distribution type are recorded after each bootstrap sampling and used as the statistics and distribution type of random variables in the subsequent Monte Carlo calculation. 
3.2. PSO-ELM Model. Extreme learning machine (ELM) is a new type of feedforward single hidden layer neural network. In addition to inheriting the good self-organization and selfadapting ability of general neural network algorithms, it also has fewer adjustable parameters, faster speed, better prediction accuracy, strong versatility, and other advantages. The input weight $\omega_{l \times n}$ and hidden layer threshold $b_{l \times n}$ are randomly selected, and then the input quantity $X_{n \times Q}$, output weight $\beta_{l \times m}$, and excitation function $g(x)$ are combined to obtain the expression of the output $t_{j}$ :

$$
H \beta=T,
$$

where

$$
\begin{aligned}
H & =\left[\begin{array}{c}
g\left(w_{1} \cdot x_{1}+b_{1}\right) g\left(w_{2} \cdot x_{1}+b_{2}\right) \cdots g\left(w_{l} \cdot x_{1}+b_{l}\right) \\
g\left(w_{1} \cdot x_{2}+b_{1}\right) g\left(w_{2} \cdot x_{2}+b_{2}\right) \cdots g\left(w_{l} \cdot x_{2}+b_{l}\right) \\
\vdots \\
g\left(w_{1} \cdot x_{Q}+b_{1}\right) g\left(w_{2} \cdot x_{Q}+b_{2}\right) \cdots g\left(w_{l} \cdot x_{Q}+b_{l}\right)
\end{array}\right], \\
\beta & =\left[\begin{array}{ccc}
\beta_{11} & \cdots & \beta_{1 m} \\
\vdots & \ddots & \vdots \\
\beta_{l 1} & \cdots & \beta_{l m}
\end{array}\right], \\
T & =\left[\begin{array}{c}
t_{1 j} \\
t_{2 j} \\
\vdots \\
t_{m j}
\end{array}\right] . \\
\beta & =H^{+} T .
\end{aligned}
$$

In ELM, the input weight hidden layer threshold is randomly selected, and the excitation function and input are known. Therefore, the training of the extreme learning machine is to calculate the output weight through equation (7), and then use it to perform predictions.

PSO is an intelligent optimization algorithm that simulates the foraging behavior of a bird colony to achieve swarm optimization. This method treats the solution of each problem as a particle. The distance between the particle's spatial position and the target is used as the fitness value, and each particle has a specific moving direction and speed. The PSO algorithm updates the speed and fitness in every search by tracking the individual's extreme values (Pbest, the optimal position of fitness values calculated from the positions of individuals) and the group's extreme values (Gbest, the optimal position of fitness of all particles in the population) until the termination requirements are met. The termination condition can be the number of iterations, the extreme value error of two consecutive searches below a specific tolerance value, or a mixture of both.

The extreme learning machine algorithm optimized by particle swarm optimization is shown in Table 2 .

3.3. Membership Function of Safety Factor in Dump Sites. Monte Carlo reliability analysis considers that there are only three states in a slope: limit equilibrium state $(Z=1)$, unstable state $(Z<1)$, and stable state $(Z>1)$. However, the corresponding relationship between the safety factor and the stable situation in the actual soil slope is fuzzy and uncertain, which means the slope has a fuzzy interval of intermediate transition between completely unstable and completely stable. Even if the safety factor is greater than 1 or even 1.2, it may become unstable; less than 1 also has the possibility of stability. Therefore, the way the Monte Carlo method estimates slope failure probability based on the proportion of statistical failure times to total simulation times may be biased, so it is necessary to introduce the stability membership function $\mu(Z)$ of the safety factor to judge the stability of soil slope equation (2) can be improved as

$$
P_{f}=\frac{\sum_{i=1}^{N} \mu_{i}(Z)}{N} .
$$

As the name implies, the membership function is the degree to which the safety factor belongs to the stable state of the slope, $\mu(Z) \longrightarrow 0$. Slope becomes more unstable, $\mu(Z)=0.5$. The probability of slope instability and stability is 0.5. At this time, the fuzziness is the strongest and the stability state is the most difficult to judge. At $\mu(Z) \longrightarrow 1$, the slope becomes more stable.

The membership functions commonly used to characterize the stability of geotechnical engineering structures include ridge distribution, quadratic parabolic distribution, 
TABle 2: Particle swarm optimization-extreme learning machine (PSO-ELM) algorithm program.

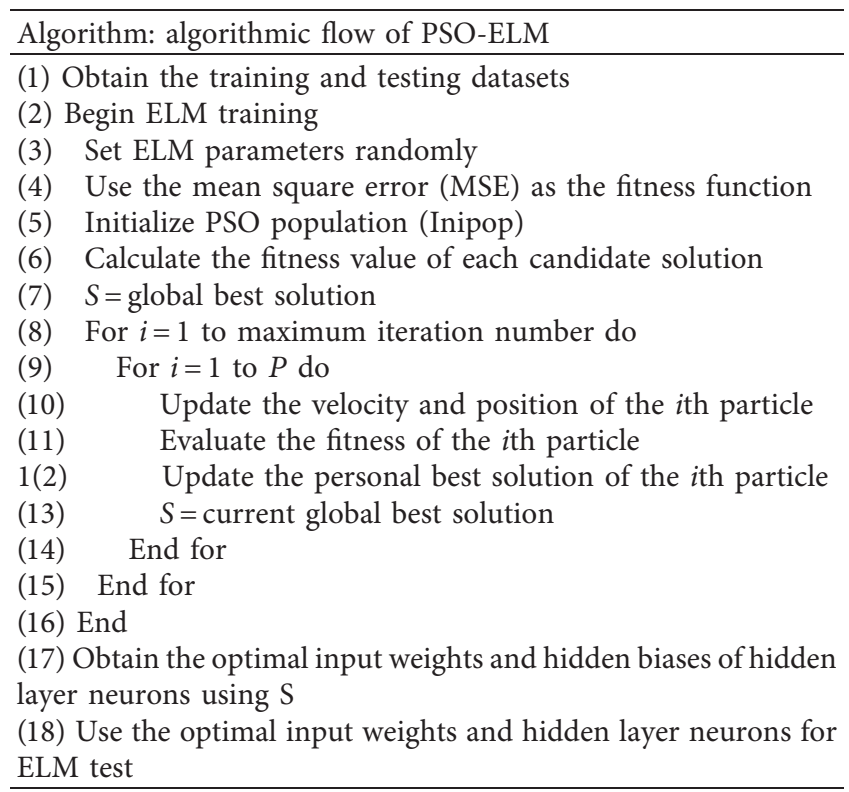

and reduced semitrapezoidal distribution. Each of these membership functions can also be divided into three types: descending, rising, and intermediate. The membership function of the safety factor for stability should express the degree to which the safety factor belongs to the concept of stability, and additionally, the slope of the graph curve should reflect the strength of the fuzziness that affects the judgment of the steady state. The smaller the safety factor, the closer $\mu(Z)$ is to 0 , the easier it is to judge that the slope is in an unstable state. Similarly, the larger the safety factor, the closer $\mu(Z)$ is to 1 , and the slope is likely to be in a stable state. The fuzziness is the strongest when the safety factor and $\mu(Z)$ are in the middle, so the curve slope of the membership function first increases and then decreases, with the characteristics of slow at both ends and steep in the middle. Based on the above characteristics and engineering application principles, the raised-ridge-shaped distribution membership function was selected as the stable membership function of the slope safety factor. The function expression is as follows:

$$
\mu\left(F_{s}\right)= \begin{cases}0, & F_{s} \leq a, \\ \frac{1}{2}+\frac{1}{2} \sin \left(\frac{\pi\left(F_{s}-b\right)}{2(b-a)}\right), & a<F_{s} \leq b, \\ \frac{1}{2}+\frac{1}{2} \sin \left(\frac{\pi\left(F_{s}-b\right)}{2(c-b)}\right), & b<F_{s} \leq c, \\ 1, & F_{s}>c .\end{cases}
$$

The steps to determine the specific form in the membership function are as follows:

Step 1: collect the corresponding relationship between the actual stability of the dump site and the value of the safety factor. We collected 48 sets of statistical data on the stability factors of different dumps in China, as shown in Table 3. In the data, the highest value of safety factor of unstable slope is 1.21 , and the lowest value is 0.92 ; therefore, it can be assumed that a dump slope with safety factor greater than 1.21 must be stable, and a dump slope with safety factor less than 0.92 can no longer remain stable. The median value of 1.065 is used to divide the safety factor into two intervals. The stable state of dump sites changes most obviously near 1.065 , so the stability state of a dump slope with a safety factor of 1.065 is the fuzziest, and the corresponding membership degree should be 0.5 .

Step 2: preliminarily determine the undetermined coefficient of the membership function. According to the analysis given in Step 1, $a=0.92, c=1.21, b=(a+c) / 2=1.065, \quad$ and substituting into equation (9), the membership function of the safety factor of raised-ridge-shaped distribution can be expressed as

$$
\mu F_{s}= \begin{cases}0, & F_{s} \leq 0.92 \\ 0.5+0.5 \sin \left(\frac{\pi\left(F_{s}-1.065\right)}{0.29}\right), & 0.92<F_{s} \leq 1.21 \\ 1, & F_{s}>1.21\end{cases}
$$

Figure 5 shows a ridge-shaped distribution function diagram of the relationship between the safety factor and the steady state membership based on the collected data. The point with a membership value of 1 corresponds to the stable state of the dump, and the point with a membership value of 0 indicates an unstable state. The function diagram can fit the data points of the dump sites well and follow the slope membership function law mentioned above.

Step 3: use the degree of conformity between the statistical law of the dump sites and the safety factor interval, with the membership interval corresponding to the fuzzy language value, to judge whether the membership function determined in Step 1 and 2 is practical.

There are nine commonly used fuzzy linguistic values to describe a certain state; however, due to the small amount of collected samples, the number of samples in each fuzzy subset would be too small, which could cause fluctuations in statistical results, so it is necessary to reduce the fuzzy language subset describing slope stability. In this paper, five fuzzy linguistic values of stable $\pi_{1}$, basically stable $\pi_{2}$, critical $\pi_{3}$, basically unstable $\pi_{4}$, and unstable $\pi_{5}$ were selected to describe the stability state of the dump slope, and the membership interval calculation formula of fuzzy linguistic value in [37] was reduced to 5, as shown in equation (11), where $a$ is a constant used to separate the interval, $a \in[0.5$, $1]$, and here we take $a=0.51$ : 
TABLE 3: Examples of safety factor and stability of soil slope of dump.

\begin{tabular}{|c|c|c|c|c|c|}
\hline Actual state & Safety factor & Actual state & Safety factor & Actual state & Safety factor \\
\hline Stable & 1.877 & Stable & 1.242 & Unstable & 1.078 \\
\hline Stable & 1.635 & Stable & 1.241 & Stable & 1.07 \\
\hline Stable & 1.52 & Stable & 1.228 & Stable & 1.07 \\
\hline Stable & 1.468 & Stable & 1.22 & Unstable & 1.06 \\
\hline Stable & 1.421 & Unstable & 1.21 & Unstable & 1.05 \\
\hline Stable & 1.404 & Stable & 1.2 & Unstable & 1.02 \\
\hline Stable & 1.39 & Stable & 1.2 & Unstable & 1.015 \\
\hline Stable & 1.39 & Stable & 1.19 & Unstable & 1.01 \\
\hline Stable & 1.389 & Stable & 1.173 & Unstable & 1.003 \\
\hline Stable & 1.356 & Unstable & 1.16 & Unstable & 0.98 \\
\hline Stable & 1.351 & Unstable & 1.13 & Unstable & 0.96 \\
\hline Stable & 1.337 & Unstable & 1.112 & Stable & 0.92 \\
\hline Stable & 1.315 & Unstable & 1.11 & Unstable & 0.89 \\
\hline Stable & 1.31 & Unstable & 1.1 & Unstable & 0.86 \\
\hline Stable & 1.27 & Unstable & 1.08 & Unstable & 0.8 \\
\hline Stable & 1.25 & Stable & 1.082 & Unstable & 0.480 \\
\hline
\end{tabular}

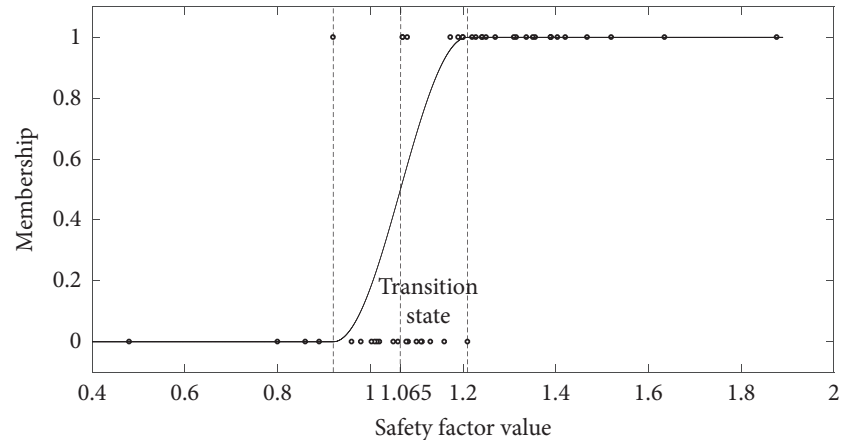

Figure 5: Membership function graph of safety factor.

$$
\left\{\begin{array}{l}
\pi_{1}=\{1\} \\
\pi_{2}=[0.2806+0.7194 a, 1], \\
\pi_{3}=[0.7194-0.7194 a, 0.2806+0.7294 a], \\
\pi_{4}=[0,0.7194-0.7194 a], \\
\pi_{5}=\{0\}
\end{array}\right.
$$

The safety factor interval corresponding to the fuzzy language value of the dump slope stability can be obtained by substituting each end value of the membership interval into equation (12). Table 4 lists the statistical results of the dump sites' samples, the membership degree interval, and the safety factor interval, where $n_{i}$ represents the number of slopes in the dump in a stable state in the $\pi_{i}$ safety factor interval and $N_{i}$ is the number of slope instances in the corresponding safety factor interval. If the membership function is selected reasonably, the value of $n_{i} / N_{i}$ increases to 1 as the membership interval approaches 1 :

$$
F_{s}=\frac{0.29 * \arcsin 2\left(\mu\left(F_{s}\right)-0.5\right)}{\pi}+1.065 .
$$

It can be seen from Table 4 that the $n_{i} / N_{i}$ value is in good agreement with the membership interval corresponding to the $i$ th fuzzy language value. The closer it is to the steady state, the closer its value is to 1 . Therefore, it can be considered that the slope stability membership function proposed in this paper according to formula (10) can reflect the overall law of the slope stability of the dump site with the change of the safety factor, which can be used to improve the criterion of the subsequent Monte Carlo calculation state function.

The flowchart of specific application steps of methods is shown in Figure 6.

\section{Application}

4.1. Bootstrap Statistical Uncertainty Simulation. This paper used MATLAB to perform bootstrap sampling on the original sample and selected $N_{B}=10^{4}$ as the number of subsamples (also the number of samples) based on ensuring good convergence and computational efficiency. Box-andwhisker plots of 20 randomly selected bootstrap subsamples and the original sample are shown in Figure 7. It can be seen that the generated subsamples perfectly retain the data information of the original sample.

For this procedure, 10,000 simulations generated 10,000 subsamples, corresponding to the mean, standard deviation, and AIC value of 10,000 simulated samples. Figures 8 and 9 and Table 5 show the distribution of the subsamples' mean and standard deviation, and the number of times that the four common probability density functions are identified as the optimal distribution. It is not difficult to see that except for bedrock cohesion, for the other indicators, the distribution of the mean and standard deviation of the bootstrap subsamples is close to that of the original sample, and the optimal probability distribution function of the subsamples obtained by the bootstrap method is mostly the same as the original sample, which is normal distribution, only a few of the optimal probability distributions of the subsample are the other indicators. This shows that the bootstrap subsamples can effectively reflect the basic characteristics of the original sample data, which means that the original limited data sample has statistical uncertainty and AIC value variability. This problem may affect the selection of subsequent 
TABLE 4: Comparison of safety factor interval and statistical law of actual dump.

\begin{tabular}{lccc}
\hline Fuzzy linguistic value & & $a=0.51$ & \\
& Membership interval & Safety factor interval & $n_{i} / N_{i}$ \\
\hline Stable & $\{1\}$ & {$[1.21,+\infty)$} & $22 / 22$ \\
Basically stable & {$[0.653,1]$} & {$[1.093,1.21)$} & $4 / 9$ \\
Critical & {$[0.316,0.653]$} & {$[1.03,1.093)$} & $3 / 7$ \\
Basically unstable & {$[0,0.316]$} & {$[0.92,1.03)$} & $1 / 6$ \\
Unstable & $\{0\}$ & {$[0,0.92)$} & $0 / 4$ \\
\hline
\end{tabular}

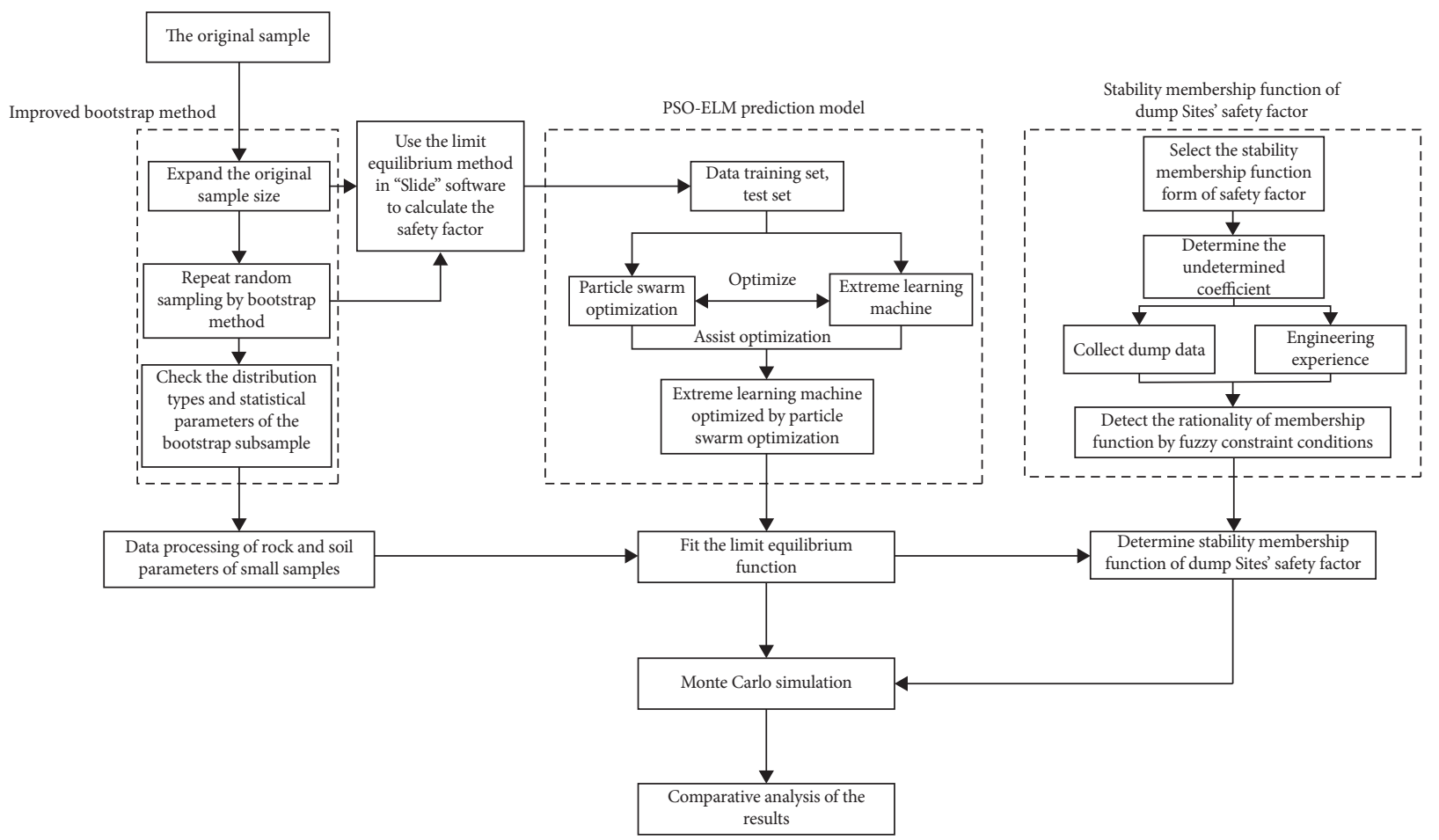

Figure 6: Operation flowchart.

distribution parameters and probability distribution function types, and the bootstrap method can simulate such variability.

\subsection{Realizing the PSO-ELM-MCS Model in MATLAB.} This paper uses the Janbu simplified method to calculate the safety factor of the sample to form the training and test sets and train the PSO-ELM model to achieve the purpose of replacing the original limit equilibrium function. The specific steps are as follows:

Step 1: determine training and test sets. In addition to the 34 sets of original samples, 44 sets of samples randomly selected from the bootstrap subsamples were substituted in the Slide software to calculate the safety factor to form 70 sets of training samples and 8 sets of test samples.
Step 2: set initial parameters. Six rock and soil parameters corresponded to one safety factor value in each group of samples, so there were six input layer units of the PSO-ELM model and one output layer unit. If the number of hidden layer units is too high, it will lead to excess performance, and if the number is too low, it will affect the prediction accuracy. After many calculations, we decided to set the number to 25 . The learning factor $C_{1}=C_{2}=1.49$, the sigma function was selected as the excitation function, and the linearly decreasing weight that can account for both local and global search was selected as the inertial weight.

Step 3: train and test models. The 70 sets of training samples obtained in Step 1 were combined with the PSO model to start training, and the weights and thresholds obtained after training were assigned to the ELM model, then the test samples were substituted into 

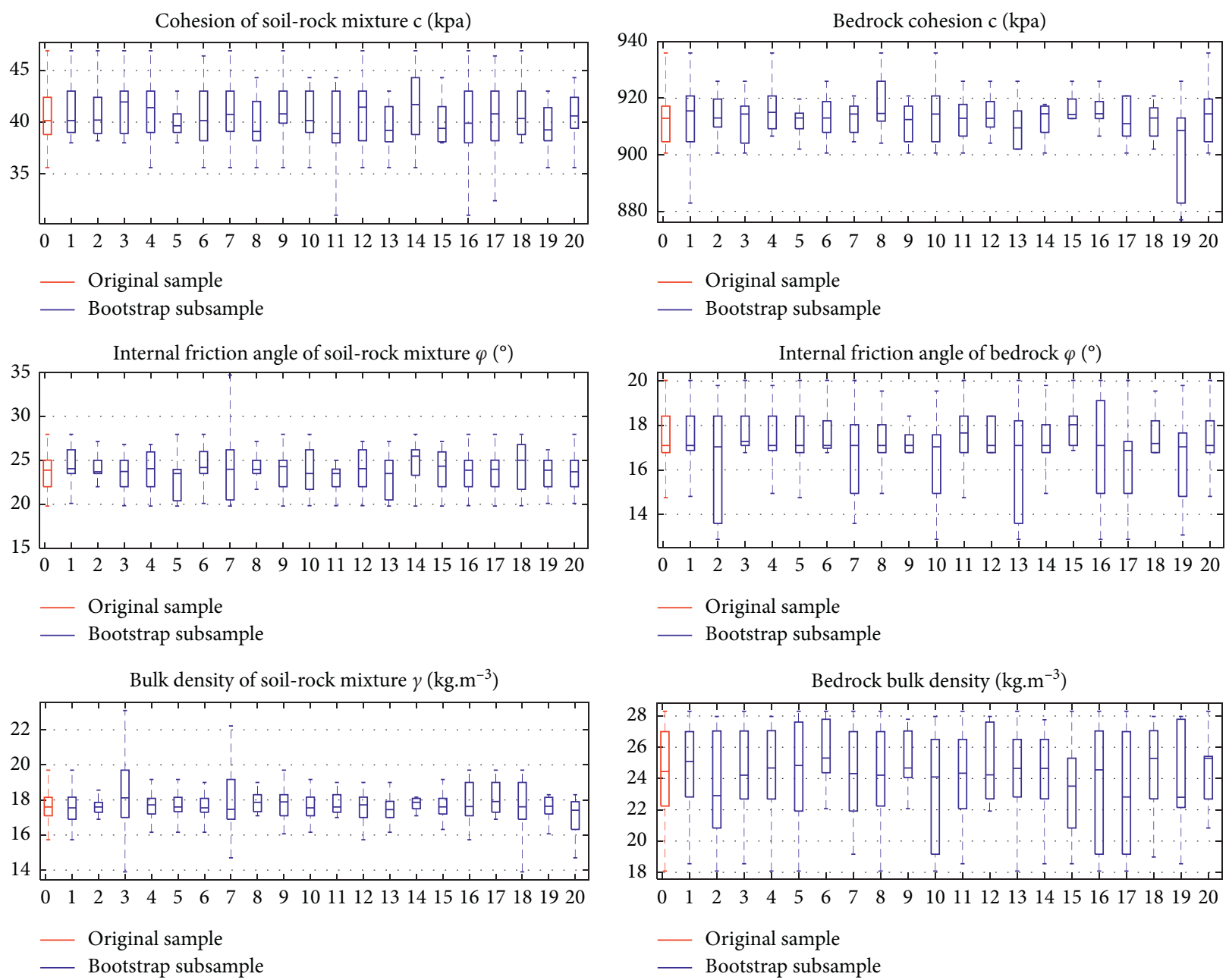

FIgURE 7: Box-and-whisker diagrams of original sample and bootstrap subsample data.

the predicted value of the safety factor to test the accuracy.

Figure 10 shows a comparison between the predicted and real values of the PSO-ELM model, as well as the predicted value of ordinary ELM. The predicted values of the safety factor obtained by the two models were not much different from the true value, but the PSO-ELM model was better than the ELM model in terms of the root mean square error (RMSE) of prediction accuracy or the coefficient of determination $\left(R^{2}\right)$, which means particle swarm algorithm optimization of extreme learning machine does improve accuracy. The reliability analysis result obtained by running the PSO-ELM-MCS method in MATLAB was as follows: probability of failure $P_{f}=15.02 \%$, reliability index $\mathrm{RI}=1.0356$, and average safety factor 1.0454 , which are highly consistent with the results obtained by the Slide software in the previous paper, indicating that the PSO-ELM model can perfectly fit the original Monte Carlo method to express the functional of the relationship between soil parameters and safety factors and reliability indicators. Meanwhile, the time to obtain the safety factor by the limit equilibrium method and the PSO-ELM model in MATLAB was statistically compared, and it was found that the efficiency of the latter was significantly better. The PSO-ELM model only required $0.0741 \mathrm{~s}$, while the limit equilibrium method took $12.03 \mathrm{~s}$.

4.3. The Analysis Result of MCS Method after Adding Membership Function. Figure 11 shows the calculation results of the improved PSO-ELM-MCS model after adding the slope stability membership function as the Monte Carlo calculation stable state criterion and expresses the relationship between the safety factor value and the membership degree. Comparing the probability of failure $P_{f}=36.85 \%$ and reliability index $\beta=0.34$ with the calculation results of the PSO-ELM-MCS model $\left(P_{f}=15.02 \%, \beta=1.0356\right)$, it can be found that the failure probability of the dump site is large improved, and reliability is significantly decreased. Comparing the reliability calculation results obtained by different limit equilibrium methods (shown in Table 6), it is found that probability of failure and reliability indicators maintain good consistency under different limit equilibrium methods, which is obviously different from the previous results obtained by using ordinary Monte Carlo reliability analysis 

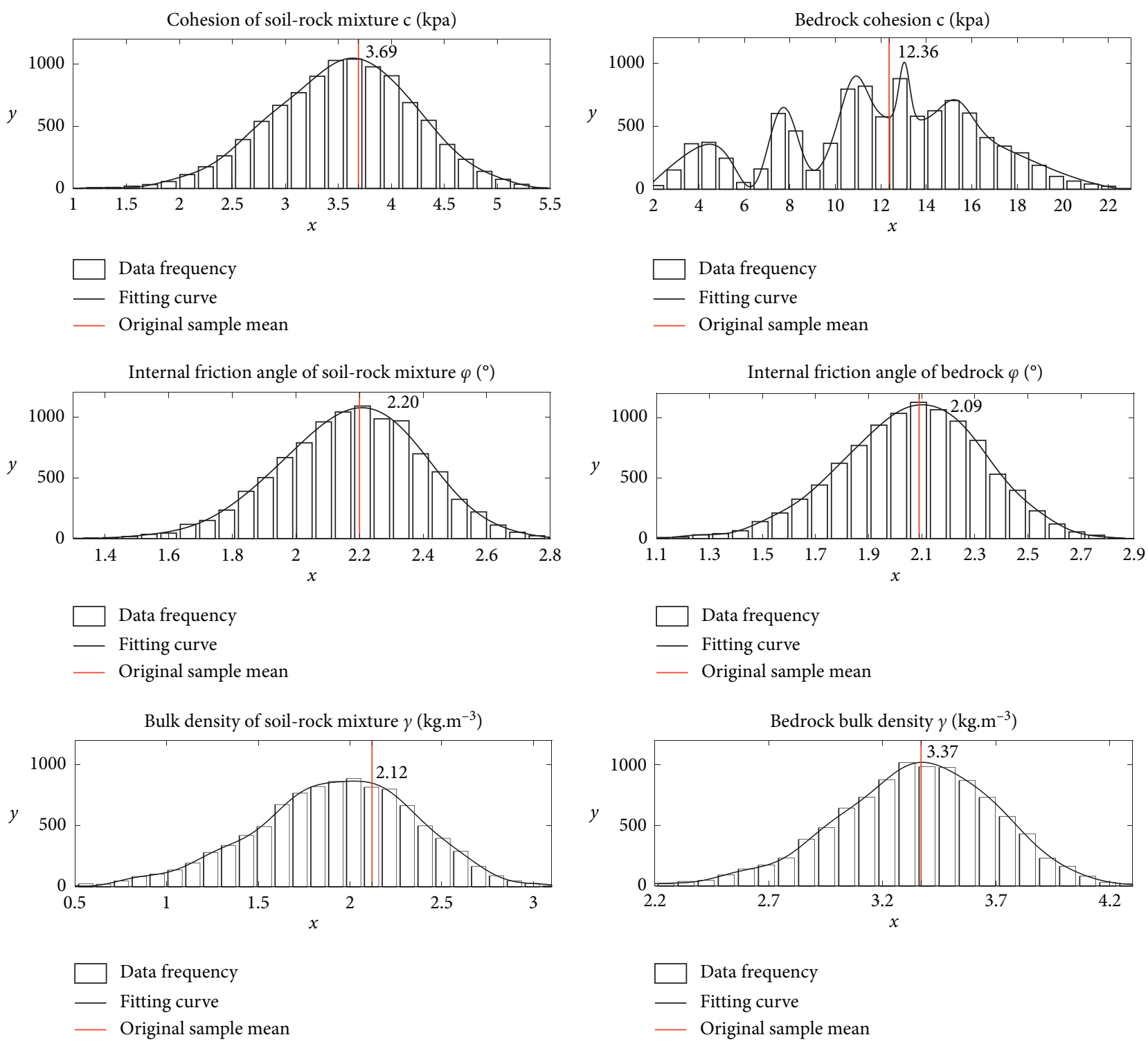

FIGURE 8: Standard deviation distribution of bootstrap subsamples.

(the relative error dropped from more than $90 \%$ to about $3 \%)$. That is to say, the results of Monte Carlo calculation with the stability membership function of the safety factor added are closer to reality than the traditional Monte Carlo reliability calculation, and it will not have the illusion of stability for simulators and engineers.

4.4. Monte Carlo Calculation Combined with PSO-ELM, Bootstrap Method, and Fuzzy Membership Function. This paper calculated the probability of failure $P_{f, i}$ and reliability index $\beta_{i}\left(i=1,2,3, \ldots, N_{B}\right)$ of each bootstrap subsample and obtained the distribution probability density function and confidence interval (using the reliability index and the $5 \%$ and $95 \%$ quantile values of failure probability as the upper and lower limits of the $90 \%$ two-sided confidence interval), and the results as shown in Figure 12 and Table 7.
It can be seen that the reliability index of the dump site basically varies between -0.5 and 1 , and the probability is the highest near 0.25 , with an average value of 0.243 , lower than the average value of 0.34 without bootstrap sampling. The probability of failure varies between 0.1 and 0.8 , with the highest probability near 0.4 , and the average value is 0.4075 , slightly higher than the 0.3664 without bootstrap sampling. This shows that the reliability index and failure probability obtained by the ordinary MCS method may have variability, and the bootstrap method can simulate this variability. In addition, compared to the MCS method, which generally only obtains a single reliability index and failure probability value, the MCS method combined with bootstrap can express the reliability index and probability of failure as a twosided confidence interval with a certain confidence level, which can reflect the actual reliability level of the dump slope. 

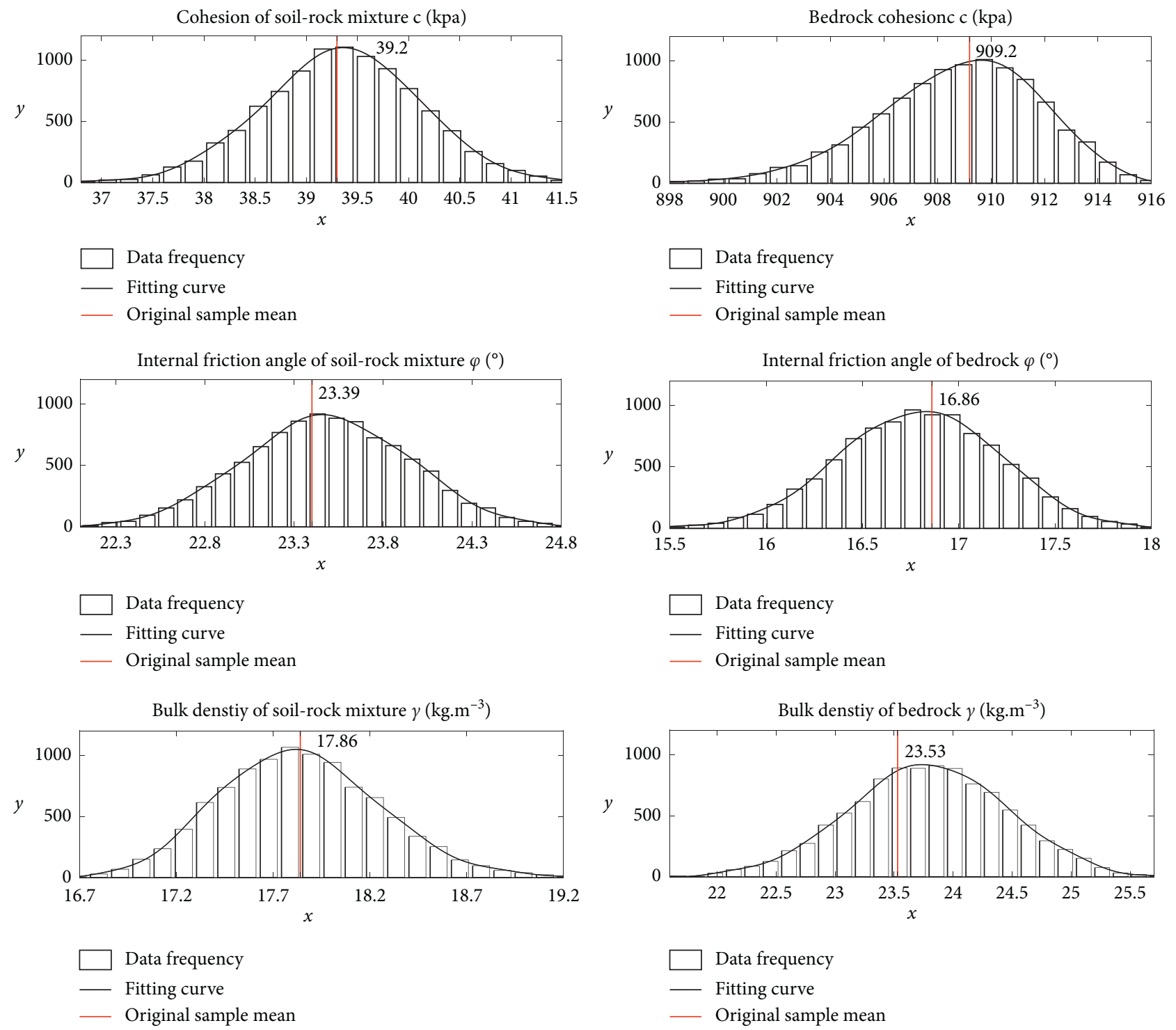

FIGURE 9: Mean distribution of bootstrap subsamples.

TABLE 5: Number of times that four common probability density functions are identified as optimal distribution.

\begin{tabular}{lcccccc}
\hline $\begin{array}{l}\text { Distribution } \\
\text { type }\end{array}$ & $\begin{array}{c}\text { Cohesion of soil-rock } \\
\text { mixture }(\mathrm{c}(\mathrm{kPa}))\end{array}$ & $\begin{array}{c}\text { Internal friction } \\
\text { angle of soil-rock } \\
\text { mixture }\left(\varphi /()^{\circ}\right)\end{array}$ & $\begin{array}{c}\text { Bulk density of soil- } \\
\text { rock mixture } \\
\left(\gamma /\left(\mathrm{kN} \cdot \mathrm{m}^{-3}\right)\right)\end{array}$ & $\begin{array}{c}\text { Bedrock } \\
\text { cohesion } \\
(\mathrm{c}(\mathrm{kPa}))\end{array}$ & $\begin{array}{c}\text { Internal friction } \\
\text { angle of bedrock } \\
\left.\left(\varphi /()^{\circ}\right)\right)\end{array}$ & $\begin{array}{c}\text { Bedrock bulk } \\
\text { density } \\
\left(\gamma /\left(\mathrm{kN} \cdot \mathrm{m}^{-3}\right)\right)\end{array}$ \\
\hline $\begin{array}{l}\text { Normal } \\
\text { Lognormal }\end{array}$ & 9837 & 9918 & 9983 & 9107 & 9896 \\
Extreme value & 163 & 82 & 17 & 625 & 104 & 9943 \\
I & 0 & 0 & 0 & 113 & 0 & 57 \\
Wilber & 0 & 0 & 0 & 155 & 0 \\
\hline
\end{tabular}




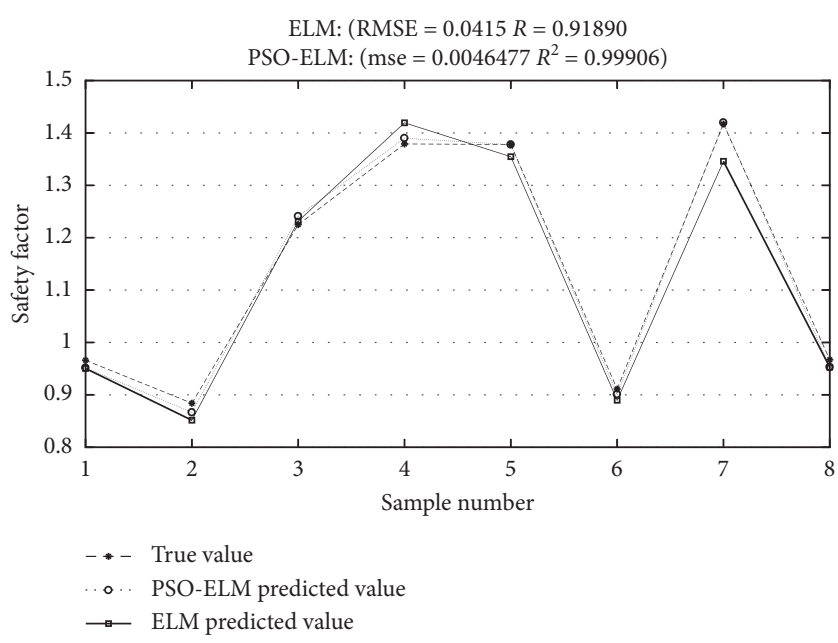

Figure 10: Comparison of prediction results of safety factor (true value and PSO-ELM and ELM).

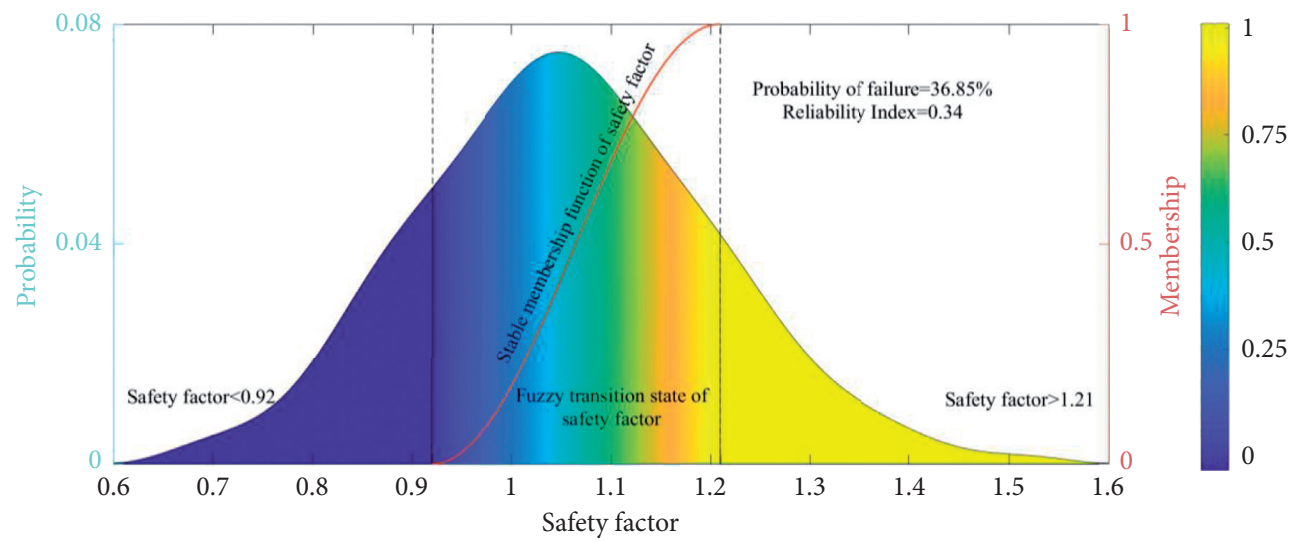

Figure 11: Monte Carlo calculation results after adding safety coefficient stable membership function.

TABLE 6: Reliability calculation results of different limit equilibrium methods.

\begin{tabular}{|c|c|c|c|c|c|}
\hline Type of limit equilibrium method & & $\begin{array}{c}\text { Janbu } \\
\text { simplified }\end{array}$ & $\begin{array}{c}\text { Ordinary } \\
\text { (Fellenius) }\end{array}$ & $\begin{array}{c}\text { Bishop } \\
\text { simplified }\end{array}$ & Spencer \\
\hline \multirow{2}{*}{ Original MCS method } & RI & 1.035 & 1.288 & 2.266 & 2.246 \\
\hline & $\mathrm{Pf}$ & $15.02 \%$ & $9.74 \%$ & $1.14 \%$ & $1.3 \%$ \\
\hline \multirow{2}{*}{$\begin{array}{l}\text { MCS method with stable membership function of safety factor } \\
\text { added }\end{array}$} & RI & 0.34 & 0.4067 & 0.4272 & 0.4097 \\
\hline & Pf & $36.85 \%$ & $34.21 \%$ & $33.46 \%$ & $34.1 \%$ \\
\hline
\end{tabular}
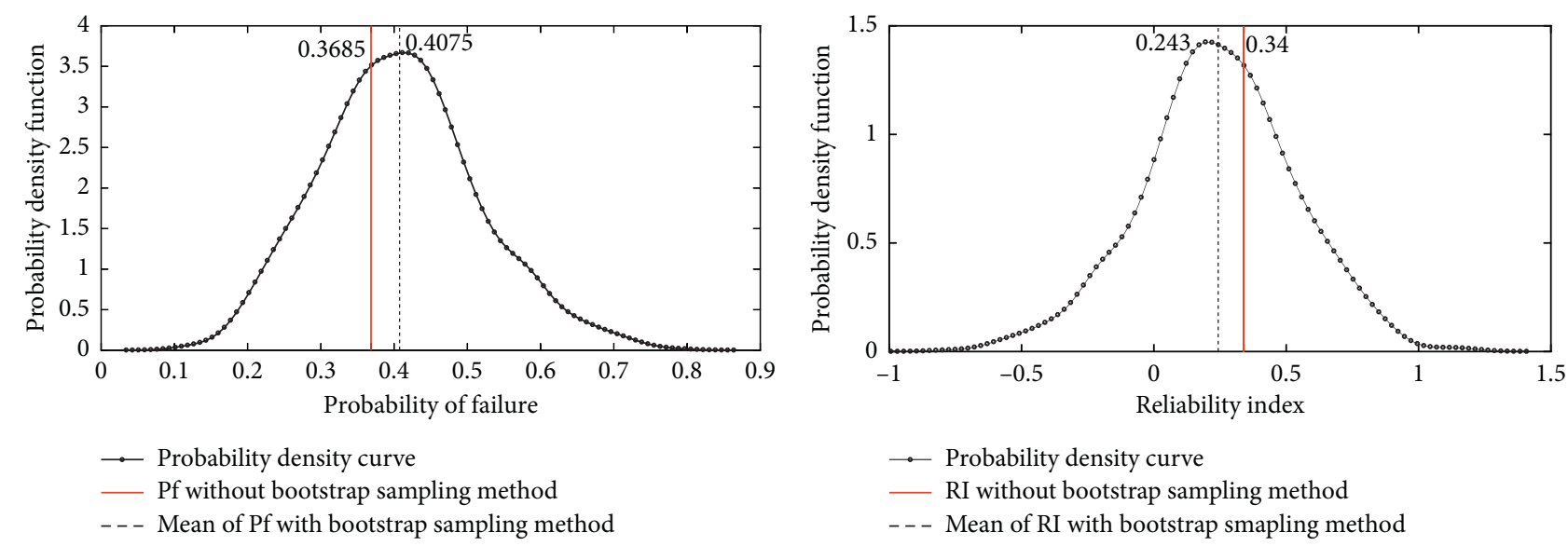

(a) (b)

Figure 12: Probability density function of (a) failure probability $P_{f}$ and (b) reliability index $\beta$ of the dump site. 
TABLE 7: Bootstrap method calculation results.

\begin{tabular}{lccccc}
\hline $\begin{array}{l}\text { Probability of failure } P_{f} \\
\text { Mean }\end{array}$ & $90 \%$ confidence interval of mean & Standard deviation & Mean & $90 \%$ confidence interval of mean & Standard deviation \\
\hline $40.75 \%$ & {$[41.43 \%, 40.08 \%]$} & 0.108 & 0.243 & {$[0.2249,0.2611]$} & 0.291 \\
\hline
\end{tabular}

\section{Discussion and Conclusion}

This paper proposed an improved Monte Carlo method that uses improved bootstrap methods to process small samples of geotechnical data, applies particle swarm optimization (PSO)-optimized extreme learning machine (ELM) to fit limit equilibrium method function, and constructs the safety factor membership function of the dump site considering the fuzzy transition interval, the results of each method combination are compared and analyzed, and the conclusions are as follows:

The MCS method using the PSO-ELM model to replace the original functional function can greatly improve efficiency on the basis of ensuring accuracy. The time consumed changed from the original $63005.44 \mathrm{~s}$ to $45.312 \mathrm{~s}$, and the probability of failure $(15.25 \%$ and $15.02 \%)$ and the reliability index (1.027 and 1.036) are almost the same, which proves that the artificial intelligence and neural network algorithms have good self-learning abilities and are effective at fitting implicit functional functions.

After the safety factor membership function of the dump site was added to the Monte Carlo method, the fluctuation of reliability index and probability of failure of the Nanpo dump site under different limit equilibrium methods was effectively improved, and the results showed an inclination toward slope instability (the failure probability of $36.64 \%$ and reliability index of 0.34 are significantly lower than the $15.02 \%$ and 1.036 without the membership function), which is closer to the situation at the actual dump site. This shows that the addition of a fuzzy transition zone of safety factor can take into account the uncertainty and gradualness of the slope in the process of failure, reduce the fluctuation of calculation results to a certain extent, and make it more real and effective.

Although the MCS method combined with the bootstrap method has a lot of repeated calculation work, the time changed from $44.519 \mathrm{~s}$ to $20275.23 \mathrm{~s}$, but time was exchanged for accuracy, and the bootstrap subsample was generated to simulate the uncertainty brought by the small sample size of the experimental data (uncertainty of sample mean, standard deviation, optimal probability density distribution, reliability index, and failure probability), making the reliability calculation result change from a single value to a confidence interval with fuzzy characteristics, which is closer to reality. The average values of reliability analysis obtained by the improved Monte Carlo method based on bootstrap in the second-phase dump site of the mine are $P_{f}=40.75 \%$ and $\beta=0.243$, which indicates a hazardous situation that requires immediate protective measures. The dump site immediately implemented preventive measures of antislip steel rail piles plus spoil grading and classified discharge to avoid the aggravation of displacement and the occurrence of landslides.

On summary, the method proposed in this paper can be used in the reliability analysis of the dump, and the effect is better than the traditional MCS method.

\section{Limitation}

However, the methods and research in this paper still have some shortcomings that could be improved. Such as the calculation process of MCS is not simplified and still consumes a lot of time, and the fuzzy membership function of the dump safety coefficient determined in this paper may still be subjective because of insufficient data collection and requires a professional authority to collect thousands of waste dump examples to reduce uncertainty. Follow-up studies will be carried out to improve the above deficiencies.

\section{Data Availability}

The soil and rock data used to support the findings of this study have been deposited in the (Research on Key Technology of Stability and Safety Control of Large Dump in Open-Pit Mine) repository (Wang L, Research on Key Technologies of Stability and Safety Control of Large OpenPit Mine Dump, 2015, University of Science and Technology Beijing).

\section{Conflicts of Interest}

The authors declare that they have no conflicts of interest.

\section{References}

[1] L. Wang, Research on Key Technologies of Stability and Safety Control of Large Open-Pit Mine Dump, University of Science and Technology, Beijing, China, 2015.

[2] R. Suchomel and D. Marin, "Comparison of different probabilistic methods for predicting stability of a slope in spatially variable c soil," Computers \& Geotechnics, vol. 37, no. 1, pp. 132-140, 2010.

[3] B. K. Low and W. H. Tang, "Reliability analysis using objectoriented constrained optimization," Structural Safety, vol. 26, no. 1, pp. 69-89, 2004.

[4] J. Ji, "A simplified approach for modeling spatial variability of undrained shear strength in out-plane failure mode of earth embankment," Engineering Geology, vol. 183, pp. 315-323, 2014. 
[5] B. K. Low and W. H. Tang, "Probabilistic slope analysis using janbu's generalized procedure of slices," Computers and Geotechnics, vol. 21, no. 2, pp. 121-142, 1997.

[6] B. K. Low, "Reliability analysis of rock slopes involving correlated nonnormals," International Journal of Rock Mechanics and Mining Sciences, vol. 44, no. 6, pp. 922-935, 2007.

[7] P. Zeng and R. Jimenez, "An approximation to the reliability of series geotechnical systems using a linearization approach," Computers and Geotechnics, vol. 62, pp. 304-309, 2014.

[8] B. K. Low, "FORM, SORM, and spatial modeling in geotechnical engineering," Structural Safety, vol. 49, pp. 56-64, 2014.

[9] S. E. Cho, "Effects of spatial variability of soil properties on slope stability," Engineering Geology, vol. 92, no. 3, pp. 97-109, 2007.

[10] S. E. Cho, "Probabilistic assessment of slope stability that considers the spatial variability of soil properties," Journal of Geotechnical and Geoenvironmental Engineering, vol. 136, no. 7, pp. 975-984, 2010.

[11] S. H. Jiang, "Efficient system reliability analysis of slope stability in spatially variable soils using Monte Carlo simulation," Journal of Geotechnical \& Geoenvironmental Engineering, vol. 141, no. 2, Article ID 4014096, 2015.

[12] H. El-Ramly, N. R. Morgenstern, and D. M. Cruden, "Probabilistic slope stability analysis for practice," Canadian Geotechnical Journal, vol. 39, no. 3, pp. 665-683, 2002.

[13] H. El-Ramly, N. R. Morgenstern, and D. M. Cruden, "Probabilistic assessment of stability of a cut slope in residual soil," Géotechnique, vol. 55, no. 1, pp. 77-84, 2005.

[14] J. Huang, D. V. Griffiths, and G. A. Fenton, "System reliability of slopes by RFEM," Soils and Foundations, vol. 50, no. 3, pp. 343-353, 2010.

[15] F. S. Wong, "Slope reliability and response surface method," Journal of Geotechnical Engineering, vol. 111, no. 1, pp. 32-53, 1985.

[16] B. Xu and B. K. Low, "Probabilistic stability analyses of embankments based on finite-element method," Journal of Geotechnical and Geoenvironmental Engineering, vol. 132, no. 11, pp. 1444-1454, 2006.

[17] J. Zhang, L. M. Zhang, and W. H. Tang, "New methods for system reliability analysis of soil slopes," Canadian Geotechnical Journal, vol. 48, no. 7, pp. 1138-1148, 2011.

[18] J. Zhang, L. M. Zhang, and W. H. Tang, "Kriging numerical models for geotechnical reliability analysis," Soils and Foundations, vol. 51, no. 6, pp. 1169-1177, 2011.

[19] J. Zhang, H. W. Huang, C. H. Juang, and D. Q. Li, "Extension of hassan and wolff method for system reliability analysis of soil slopes," Engineering Geology, vol. 160, pp. 81-88, 2013.

[20] J. Zhang, H. W. Huang, and K. K. Phoon, "Application of the kriging-based response surface method to the system reliability of soil slopes," Journal of Geotechnical and Geoenvironmental Engineering, vol. 139, no. 4, pp. 651-655, 2013.

[21] D. Q. Li, "Reliability analysis of slopes considering spatial variability of soil parameters using non-intrusive stochastic finite element method," Journal of Geotechnical Engineering, vol. 35, no. 8, pp. 1413-1422, 2013.

[22] S.-H. Jiang, D.-Q. Li, L.-M. Zhang, and C.-B. Zhou, "Slope reliability analysis considering spatially variable shear strength parameters using a non-intrusive stochastic finite element method," Engineering Geology, vol. 168, pp. 120-128, 2014.

[23] D.-Q. Li, S.-H. Jiang, Z.-J. Cao, W. Zhou, C.-B. Zhou, and L.-M. Zhang, "A multiple response-surface method for slope reliability analysis considering spatial variability of soil properties," Engineering Geology, vol. 187, pp. 60-72, 2015.

[24] T. T. He, "Support vector machine method for slope reliability analysis," Rock and Soil Mechanics, vol. 11, pp. 232-239, 2013.

[25] X.-H. Tan, M.-F. Shen, X.-L. Hou, D. Li, and N. Hu, "Response surface method of reliability analysis and its application in slope stability analysis," Geotechnical and Geological Engineering, vol. 31, no. 4, pp. 1011-1025, 2013.

[26] G. S. Su, "Gaussian process dynamic response surface method for slope failure probability estimation," Rock and Soil Mechanics, vol. 12, pp. 3592-3601, 2014.

[27] F. Kang and J. Li, "Artificial bee colony algorithm optimized support vector regression for system reliability analysis of slopes," Journal of Computing in Civil Engineering, vol. 30, no. 3, Article ID 4015040, 2016.

[28] S. E. Cho, "Probabilistic stability analyses of slopes using the ANN-based response surface," Computers and Geotechnics, vol. 36, no. 5, pp. 787-797, 2009.

[29] Y. H. Su and H. B. Yang, "Slope stability reliability algorithm based on proxy model," Journal of Applied Mechanics, vol. 29, no. 6, pp. 705-710, 2012.

[30] Y. H. Su, "Active search method for slope stability reliability based on kriging," Journal of Geotechnical Engineering, vol. 35, no. 10, pp. 1863-1869, 2013.

[31] P. Yi, K. Wei, X. Kong, and Z. Zhu, "Cumulative PSO-kriging model for slope reliability analysis," Probabilistic Engineering Mechanics, vol. 39, pp. 39-45, 2015.

[32] Y. Wang, "Study and application of vector projection response surface for slope reliability evaluation," Journal of Geotechnical Engineering, vol. 33, no. 9, pp. 1434-1439, 2011.

[33] G. Habibagahi and M. Meidani, "Reliability of slope stability analysis evaluated using a fuzzy set approach," in Proceedings of the 5th International Conference on Civil Engineering, Ferdowsi University, Singapore, 2000.

[34] W. Y. Xu, Z. M. Jiang, and A. C. Shi, "Slope stability analysis based on fuzzy set theory," Journal of Geotechnical Engineering, vol. 25, no. 4, pp. 409-413, 2003.

[35] H. H. Jia and H. J. He, "Fuzzy random reliability analysis of slope stability," Rock and Soil Mechanics, vol. 24, no. 4, pp. 657-660, 2003.

[36] F. Lou, Fuzzy Random Reliability Analysis of Slope Safety in Open Pit Mines, Central South University, Changsha, China, 2008.

[37] H. Xu, Fuzzy Random Reliability Analysis of Slope Stability Based on Fuzzy Set Theory, Zhejiang University, Hangzhou, China, 2006.

[38] M. Anvar and M. Bahrami, "Uncertainty analysis of safety factor of embankment built on stone column improved soft soil using fuzzy logic alpha-cut technique," Computers and Geotechnics, vol. 14, pp. 101-104, 2016.

[39] T. Most and T. Knabe, "Reliability analysis of the bearing failure problem considering uncertain stochastic parameters," Computers and Geotechnics, vol. 37, no. 3, pp. 299-310, 2010.

[40] Z. Luo, S. Atamturktur, and C. H. Juang, "Bootstrapping for characterizing the effect of uncertainty in sample statistics for braced excavations," Journal of Geotechnical and Geoenvironmental Engineering, vol. 139, no. 1, pp. 13-23, 2013.

[41] X. S. Tang, "Joint distribution model identification of rock and soil parameters based on Bootstrap method," Rock and Soil Mechanics, vol. 4, pp. 913-922, 2015.

[42] H.,H. Tao, "Introduction to the hydroelectric engineering standard system of the U.S. army corps of engineers," HongShui River, vol. 2, pp. 98-101, 2010. 
[43] J. Wang, Opportunity-constrained Programming Analysis of Soil Slope Stability Based on Limit Equilibrium Method, Huazhong University of Science and Technology, Wuhan, China, 2018.

[44] Z. D. Wang, Y. H. Li, and F. Yun, "Application of annealing genetic algorithm in slope stability analysis," Highways, vol. 5, pp. 11-13, 2008.

[45] H. Akaike, "IEEE xplore abstract-a new look at the statistical model identification," IEEE Transactions on Automatic Control, vol. 19, no. 6, pp. 716-723, 1974.

[46] B. Efron and, "Bootstrap methods: another look at the jackknife," Annals of Statistics, vol. 7, no. 1, pp. 1-26, 1979.

[47] L. Jian, W. Yi, and T. Lu, "Improvement of bootstrap method for self-help sampling," Mathematical Theory and Application, vol. 1, pp. 69-72, 2006.

[48] F. Luo, "Bootstrap estimation of rock and soil parameters and slope stability analysis for small samples," Journal of Rock Mechanics and Engineering, vol. 36, no. 2, pp. 370-379, 2017. 